
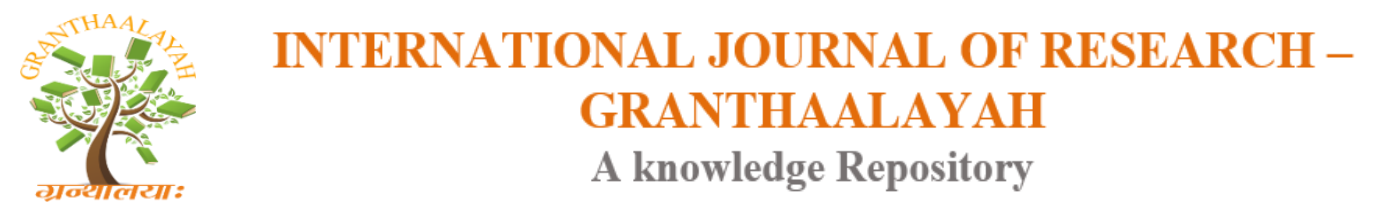

Science

\title{
COMPARISON OF A NEW VERESS NEEDLE ENTRY METHOD AND CLASSIC VERESS NEEDLE ENTRY METHOD IN GYNECOLOGIC LAPAROSCOPY: A PROSPECTIVE RANDOMIZED STUDY
}

\author{
Uğurkan Erkayıran ${ }^{* 1}$, Bülent Köstü ${ }^{2}$, Alev Özer ${ }^{3}$ \\ 1,2,3 Department of Obstetrics and Gynecology, Kahramanmaras Sutcu Imam University, School \\ of Medicine, Kahramanmaraş, Turkey
}

\begin{abstract}
Background: To compare cranial $15^{\circ}$ angulation of Veres needle to classic Veress needle entry in closed laparoscopic entry in obese patients.

Method: Patients with BMI index $>30$ were divided into two groups. Initial entry into the abdomen in Group $1(\mathrm{n}=29)$ was performed with the intraumbilical insertion of Veress needle in 90o angle relative to the horizontal plane. In Group $2(n=31)$ the Veress needle was placed intraumbilically in a cranial direction, the tip of the needle towards the thoracic cavity, with an angle of 150 to the horizontal plane. Two groups were compared with respect of the operative outcomes.

Results: In Group 2, the mean number of Veress needle entries attempt was significantly lower than Group $1(\mathrm{p}=0.01)$. Time to insertion of the Veress needle was found to be significantly shorter in Group 2 than in Group $1(\mathrm{p}<0.001)$. While entry failure occurred in 3 patients in Group $1(10.3 \%)$, no failures were monitored in any patients in Group $2(\mathrm{p}=0.01)$. Complication rate was significantly lower in Group 2 than in Group $1(\mathrm{p}=0.03)$.

Conclusion: Placement of Veress needle intraumbilically in a cranial direction at $15^{\circ}$ angle to the horizontal plane increases entry success and reduces complications.
\end{abstract}

Keywords: Laparoscopic Entry; Obese Patient; Pneumoperitoneum; Veress Needle.

Cite This Article: Uğurkan Erkayıran, Bülent Köstü, and Alev Özer. (2018). "COMPARISON OF A NEW VERESS NEEDLE ENTRY METHOD AND CLASSIC VERESS NEEDLE ENTRY METHOD IN GYNECOLOGIC LAPAROSCOPY: A PROSPECTIVE RANDOMIZED STUDY." International Journal of Research - Granthaalayah, 6(2), 74-79. https://doi.org/10.5281/zenodo.1186204.

\section{Introduction}

Laparoscopic surgery has come into widespread use in the last two decades. Compared with laparotomy, it presents benefits in terms of small incision, less postoperative pain, quicker recovery and short-term hospitalization (1). However, although no significant differences have been observed in terms of major complications, overall a $40 \%$ decrease in minor complications has been seen in laparoscopic surgeries (2). Nonetheless, major complications such as bowel, 
ureter, bladder and vascular injures may still occur (3). Approximately $50 \%$ of complications in laparoscopic surgeries occur during the initial entry (4). The laparoscopic entry techniques include classic Veress needle, direct trocar, open access and optical trocar entry systems (5).

Over the past three decades, worldwide rates of overweight and obesity have risen, with epidemic proportions reached in Western countries where rates are highest (6). While obesity was previously considered as a relative contraindication for laparoscopic surgeries, laparoscopic surgery is now the preferred method because of the benefits in terms of postoperative pain, infection and thromboembolism $(7,8)$. However, as a number of difficulties in surgery and anesthesia techniques might be experienced in laparoscopic surgeries on obese patients, many different surgical techniques have been developed which are suitable particularly for the initial entries. For example, the abdominal entry angle for Veress needle is recommended to be $45^{\circ}$ towards the pelvic cavity in non-obese patients and $90^{\circ}$ in obese patients (9). Even if the $90^{\circ}$ angle to horizontal plane is used, there has been still difficulties in achieving pneumoperitoneum safely and with minimal attempts in obese patients because of the thicker abdominal wall and of more caudal localization of umbilicus to the aortic bifurcation in obese patients compared to nonobese ones $(5,10)$.

In the current prospective study, we introduced a novel method of Veress needle entry in obese patients aiming to achieve a safer and easier entry method with lower complication rates compared to the classic Veress needle entry. In our novel method, the Veress needle was directed cranially towards the thoracic cavity and inserted with an angle of $15^{\circ}$ to the horizontal plane.

The aim of this prospective study was to compare the abdominal entry success of the Veress needle in obese patients when the tip was angled at $90^{\circ}$ in the horizontal plane or at $15^{\circ}$ in the cranial direction.

\section{Materials and Methods}

Approval for the study was granted by the Institutional Ethics Committee. Informed consent was obtained from all participants. Simple randomization was conducted using computer-generated sequence. Allocation concealment was not performed.

73 obese patients who underwent laparoscopic surgery because of benign gynecological disorders were included in the study, with obesity determined as body mass index $>30 \mathrm{~kg} / \mathrm{m}^{2}(11)$. A medical and obstetric history was taken from each patient then a physical and gynecological examination was applied. Body mass index (BMI), indications for surgery and previous surgical history were recorded for all patients. The closed Veress needle entry technique was applied during laparoscopic surgery in all cases. Patients where open entry was necessary due to 3 failed attempts at intraabdominal Veress needle entry were evaluated for the study as failures. Patients were excluded from the study if the open entry method was applied as the initial entry method, if the patient had an umbilical incision in the midline because of previous surgeries or if entry was necessary at Palmer's point. By these exclusion criteria, 60 out of 73 patients were left.

A $10 \mathrm{~mm}$ subumbilical transverse skin incision was applied, followed by blunt dissection of the subcutaneous tissues. The skin was then elevated using towel clips on both periincisional areas. At this stage, the patients were divided into 2 groups. To the patients in Group 1 ( $n=29)$ 
abdominal entries were made with the Veress needle tip angled at $90^{\circ}$ to the horizontal plane. In Group $2(n=31)$ the tip of the Veress needle tip was angled at $15^{\circ}$ towards the cranial direction. Therefore, the tip of the needle was directed towards the thorax of the patient, not towards the pelvic cavity.

Intraperitoneal placement of the Veress needle was checked with the double click sound of the Veress needle, the aspiration test, the hanging drop of saline test and intra-abdominal pressure of $<10 \mathrm{mmHg}$. In the group where cranial angling was performed the needle angle was immediately returned to $90^{\circ}$ when abdominal entry was considered to have been achieved.

The number of Veress needle entry attempts, the abdominal insertion times, entry failures and all detected complications were compared between the two groups.

The data were analyzed using SPSS 22.0 (IBM statistics for Windows version 22, IBM Corporation, Armonk, New York, United States). The average frequency and standard deviations were determined during the data analysis. The variable compliance of normal distribution was analyzed using the Kolmogorov-Smirnov test. Parametric data were evaluated with the Independent-Samples $T$ Test. A value of $\mathrm{p}<0.05$ was considered statistically significant.

\section{Results and Discussions}

Both groups were similar at baseline in terms of age, gravida, parity, BMI and the percentage of patients with previous abdominal surgery. The number of Veress needle entry attempts in Groups 1 and 2 was determined as 1.9 and $1.3(\mathrm{p}=0.01)$, successful entry time as 188 and 105 seconds respectively $(\mathrm{p}<0.001)$. Unsuccessful entry (3 failed Veress needle entry attempts) was determined to be significantly higher in Group $1(\mathrm{p}=0.01)$ (Table 1).

Table 1: Demographic characteristics of study groups

\begin{tabular}{|l|l|l|l|}
\hline & $\begin{array}{l}\text { Group 1 } \\
(\mathbf{n = 2 9})\end{array}$ & $\begin{array}{l}\text { Group 2 } \\
(\mathbf{n = ~ 3 1})\end{array}$ & $\mathbf{p}$ \\
\hline Age $^{\mathrm{a}}$ & $45.6 \pm 8.3$ & $46.5 \pm 7.1$ & 0.368 \\
\hline Gravida $^{\mathrm{a}}$ & $4.5 \pm 1.7$ & $4.4 \pm 1.1$ & 0.766 \\
\hline Parity $^{\mathrm{a}}$ & $3.3 \pm 1.5$ & $3.2 \pm 1.3$ & 0.794 \\
\hline${\text { BMI }\left(\mathrm{kg} / \mathrm{m}^{2}\right)^{\mathrm{a}}}^{\text {Patients with previous abdominal surgeries }}{ }^{\mathrm{b}}$ & $34.1 \pm 3.3$ & $33.5 \pm 2.7$ & 0.546 \\
\hline
\end{tabular}

BMI: Body mass index, ${ }^{\mathrm{a}}$ Mean \pm Standart Deviation, ${ }^{\mathrm{b}}$ Number (\%), Group 1: Verres needle angled at $90^{\circ}$ to the horizontal plane, Group 2: Verres needle tip angled at $15^{\circ}$ towards the cranial direction.

Complications in Groups 1 and 2, were observed as bleeding in the trocar area in $2(6.8 \%)$ and 1 (3.2\%) patients and extra-peritoneal insufflations in $3(10.3 \%)$ and 1 (3.2\%) patients respectively. Conversion of procedure to open entry was required in 3 patients in Group 1 $(10.3 \%)$, and was not needed in any patient in Group 2. Trocar infection was not observed in any patients in either group. The total number of patients with complications was 8 patients $(27.5 \%)$ in Group 1 and 1 patient $(6.4 \%)$ in Group $2(\mathrm{p}=0.03)$ (Table 2). 
Table 2: Operative outcomes in study groups

\begin{tabular}{|c|c|c|c|}
\hline & Group $1(n=29)$ & Group $2(n=31)$ & p* \\
\hline Number of Veress needle entry attempts ${ }^{\mathrm{a}}$ & $1.9 \pm 0.7$ & $1.4 \pm 0.4$ & $0.01 *$ \\
\hline Time to Veress needle entry (in seconds) ${ }^{\mathrm{a}}$ & $188 \pm 67$ & $105 \pm 45$ & $<0.001^{*}$ \\
\hline Unsuccesful entries $^{b}$ & $3(10.3 \%)$ & 0 & $0.01 *$ \\
\hline \multicolumn{4}{|l|}{ Complication $^{\mathrm{b}}$} \\
\hline -Bleeding in trocar area & $2(6.8 \%)$ & $1(3.2 \%)$ & \\
\hline -Infection at trocar area & 0 & 0 & \\
\hline -Extra-peritoneal insufflation & $3(10.3 \%)$ & $1(3.2 \%)$ & \\
\hline -Omental injury & 0 & 0 & \\
\hline -Bowel injury & 0 & 0 & \\
\hline -Minor vascular injuries & $2(6.8 \%)$ & $1(3.2 \%)$ & \\
\hline -Major vascular injuries & 0 & 0 & \\
\hline -Conversion to open entry & $3(10.3 \%)$ & 0 & \\
\hline Total & $8(27.5 \%)$ & $2(6.4 \%)$ & $0.03 *$ \\
\hline
\end{tabular}

${ }^{\mathrm{a}}$ Mean \pm Standart Deviation, bNumber (\%), *Statistically significant, Group 1: Veress needle angled at $90^{\circ}$ to the horizontal plane, Group 2: Veress needle tip angled at $15^{\circ}$ towards the cranial direction.

The creation of the pneumoperitoneum and placement of laparoscopic ports remain a critical first step during endoscopic surgeries. It has been reported that $50 \%$ of complications in laparoscopic surgeries occur at this initial step (12). The most important complications are extra-peritoneal gas insufflation, omental injuries and major vascular injuries. To date, there has been still no consensus about which technique is the most optimal one for creation of pneumoperitoneum.

Due to increased abdominal wall thickness and extra-peritoneal fat tissue, reaching the abdominal cavity and the creation of pneumoperitoneum is more difficult in obese patients than non-obese patients (13). Therefore, laparoscopic surgery complications are more frequent in obese patients (10).

The number of complications increase with the increased number of Veress needle entry attempts (6). Therefore, reducing the number of Veress needle entries is the most important element in the prevention of complications.

In the current study, it was determined that the number of attemts to place Veress needle, entry time and general complications were lower in patients where the Veress needle tip was inserted at a $15^{\circ}$ angle in cranial direction compared to those patients with abdominal entry at $90^{\circ}$. Although our findings are very encouraging, the small sample size is one of the limitations.

To the best of our knowledge, there is no study in literature which has described the technique of angling the Veress needle in the cranial direction i.e. towards the thoracic cavity of the patient. In the current study, as a part of standart laparoscopy procedure in our clinic, the abdominal wall was lifted in all patients during the insertion of Veress needle. However, there has been a debate over lifting of abdominal wall in obese patients (14). Compared the results of Veress needle entries performed on elevated and non-elevated abdominal walls and concluded that there was a greater number of failed entries in the elevated abdominal wall group, especially in obese 
patients. They reported that the elevation of abdominal wall results in an increased distance between skin/subcutaneous tissue and fascia/parietal peritoneum (14). In contrary to the findings of that study, supported the lifting up of abdominal wall in obese patients while placing the Veress needle, claiming that this would distance the intraabdominal content away from the Veress needle thereby leading to a reduction in major visceral and vascular injuries (15). One of the limitation of the current study is the lack of the comparision with the nonlifting technique.

Major vessel injury is among the most feared complications of closed laparoscopic entry methods. In obese patients, the umbilicus is often located 3 to $6 \mathrm{~cm}$ caudal to the aortic bifurcation, whereas in non-obese patients, the aortic bifurcation is immediately below the umbilicus (16). Therefore, while $90^{\circ}$ vertical entry at horizontal plane is suggested for obese patients, $45^{\circ}$ is suggested for non-obese patients (9). In the current study, it was assumed that directing the Veress needle cranially towards thoracic cavity would provide a decreased traveling distance thorough the abdominal wall for the Veress needle since in obese patients fatty tissue is mainly localized in the lower segments of the abdomen. Thus, creation of pneumoperitoneum would have been achieved more easily with less number of attempts thereby with decreased complication rates compared to classic Veress needle entry using $90^{\circ}$. In accordance with our initial assumption, a significant decrease in complication rate was observed in the Group where the new technique was used. However, this outcome needs further support by large cohort sized studies.

\section{Conclusions and Recommendations}

Intraumbilical insertion of the Veress needle in a cranial direction towards the thoracic cavity at $15^{\circ}$ to the horizontal plane to create pneumoperitoneum on obese patients can be considered to help reduce the number of unsuccessful entries thereby the complication rates in closed laparoscopic entry.

\section{References}

[1] Bhave Chittawar P, Franik S, Pouwer AW et al. Minimally invasive surgical techniques versus open myomectomy for uterine fibroids. Cochrane Database Syst Rev 2014 21;10:CD004638.

[2] Chapron C, Fauconnier A, Goffinet F Et al. Laparoscopic surgery is not inherently dangerous for patients presenting with benign gynaecologic athology. Results of a meta-analysis. Hum Reprod $2002 ; 17: 1334-42$.

[3] Teerapong S, Rungaramsin P, Tanprasertkul C Et al. Major complication of gynaecological laparoscopy in Police General Hospital: a 4-year experience. J Med Assoc Thai 2012; 95:137883.

[4] Fuller J, Ashar BS, Carey-Corrado J. Trocar-associated injuries and fatalities: an analysis of 1399 reports to the FDA. J Minim Invasive Gynecol 2005; 12:302-7.

[5] Chapron C, Fauoconnier A, Goffinet F Et al. Laparoscopic surgery is not inherently dangerous for patients presenting with benign gynaecological pathology: results of meta-analysis. Hum Reprod 2002; 17:1334-42.

[6] McIlwaine K, Manwaring J, Ellett L et al. The effect of patient body mass index on surgical difficulty in gynaecological laparoscopy. Aust NZJ Obstet Gynaecol 2014; 54:564-9.

[7] Eltabbakh GH, Piver MS, Hempling RE et al. Laparoscopic surgery in obese women. Obstet Gynecol 1999; 94:704-8. 
[8] Lamvu G, Zolnoun D, Boggess J Et al. Obesity: physiologic changes and challenges during laparoscopy. Am J Obstet Gynecol 2004; 191:669-74.

[9] Vilos GA, Ternamian A, Dempster J Et al. Laparoscopic entry: a review of techniques, technologies, and complications. J Obstet Gynaecol Can 2007; 29:433-65.

[10] Compeau C, McLeod NT, Ternamian A. Laparoscopic entry: a review of Canadian general surgical practice. Can J Surg 2011; 54:315-20.

[11] Obesity and overweight. World Health Organization. Updated June 2016

[12] Pasic R, Levine RL, Wolf WM Jr. Laparoscopy in morbidly obese patients. J Am Assoc Gynecol Laparosc 1999; 6:307-12.

[13] Madan AK, Menachery S. Safety and efficacy of initial trocar placement in morbidly obese patients. Arch Surg 2006; 141:300-3.

[14] Briel JW, Plaisier PW, Meijer WS et al. Is it necessary to lift the abdominal wall when preparing a pneumoperitoneum? A randomized study. Surg Endosc 2000; 14:862-4.

[15] Kosuta M, Palmisano S, Piccinni G et al. Safety of Veress needle insertion in laparoscopic bariatric surgery. Surg Laparosc Endosc Percutan Tech. 2014 Feb;24(1):e1-4.

[16] Hurd WW, Bude RO, DeLancey JO et al. The relationship of the umbilicus to the aortic bifurcation: implications for laparoscopic technique. Obstet Gynecol 1992; 80:48-51.

*Corresponding author.

E-mail address: byugrerk@ hotmail.com 